\title{
Características del empleo informal en México, 2005 y 2020
}

\section{Characteristics of informal employment in Mexico, 2005 and 2020}

\author{
Wendy Ovando-Aldana, Celso Rodrigo Rivera-Rojo \\ y María del Carmen Salgado-Vega \\ Facultad de Economía de la Universidad Autónoma \\ del Estado de México, México
}

\begin{abstract}
Resumen
El objetivo de este documento es analizar las características del empleo informal en México en dos periodos del tiempo: 2005 y 2020. Se estudian las peculiaridades de la informalidad mediante el diseño de un modelo de regresión logística binaria considerando las variables: sexo, edad, estado civil, escolaridad, localidad, tamaño de empresa, sector y horas de trabajo. Entre los principales hallazgos se encuentran que es el tamaño de la empresa la que presenta una mayor incidencia en el empleo informal en contraste con la variable edad que presentó la menor incidencia, también, los casi nulos cambios en el peso relativo de cada una de las variables en 15 años, lo que sugiere que las políticas públicas encaminadas a disminuir este fenómeno no han incidido en los rasgos del empleo informal.
\end{abstract}

Palabras clave: Empleo, informalidad, México.

Abstract

The objective of this document is to analyze the characteristics of informal employment in Mexico in two periods of time: 2005 and 2020. The peculiarities of informality are studied through the design of a binary logistic regression model considering the variables: sex, age, state, civil, schooling, location, company size, sector, and hours of work. Among the main findings are that it is the size of the company that has a greater incidence in informal employment in contrast to the variable age that presented the lowest incidence, also, the almost zero changes in the relative weight of each of the variables in 15 years, which suggests that public policies aimed at reducing this phenomenon have not affected the characteristics of informal employment.

Keywords: Employment, informality, Mexico. 


\section{INTRODUCCIÓN}

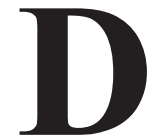

e acuerdo con la Organización Internacional del Trabajo (OIT, 2018), para 2016, más de 60 por ciento de la población ocupada en el mundo (aproximadamente dos mil millones de trabajadores) se encontraba en la economía informal, principalmente en países emergentes y en desarrollo en los que se concentra 93 por ciento del total mundial (OIT, 2018).

La economía informal incluye al sector informal y otras modalidades de empleo que no se ubican bajo el marco legal e institucional como: trabajo en actividades formales y agropecuarias, y doméstico remunerado en hogares; así como el trabajo de autoconsumo agropecuario, es decir, el empleo informal se localiza tanto en el sector formal como en el informal (INEGI, 2014).

Las implicaciones del empleo informal se pueden analizar desde dos ámbitos: en lo económico y en lo social. Por un lado, implica: costos fiscales, ahorro agregado y productividades bajas (Levy, 2018). Asimismo, su presencia influye en el ritmo del crecimiento económico (Samaniego, 2008) y representa un rasgo de poco desarrollo en una economía (Robles y Martínez, 2018). Por otro lado, significa escasa o nula protección de los trabajadores (Levy, 2018) con condiciones laborales poco favorables. Cabe señalar que la mayoría de las personas que trabajan en condiciones de informalidad no lo hacen por una cuestión de elección, más bien, por la necesidad de encontrar una fuente de ingreso que resulta, regularmente, irregular y más baja en comparación con los empleos formales (OIT, 2017).

Respecto de los trabajadores en México, más de 56 por ciento de la población ocupada se ubica en un empleo informal (INEGI, 2020a). Para el primer trimestre de 2020, uno de cada dos trabajadores se hallaba en condiciones de informalidad. Lo anterior, hace suponer que la informalidad es un rasgo estructural del mercado laboral en México. Algunos autores mencionan que representa una válvula de escape de la desocupación (OIT, 2014; Cuevas, De la Torre y Regla, 2016; Loría, Aupart y Salas, 2016); no obstante, los bajos niveles de productividad asociados a los empleos informales, han repercutido negativamente en el crecimiento económico de largo plazo (Loría, Aupart y Salas, 2016).

De acuerdo con algunas investigaciones, existen ciertas particularidades asociadas con el empleo informal, entre las que se incluyen: ser mujer (Rei y Bhattacharya, 2008; Cuevas, De la Torre y Regla, 2016; OIT, 2018; Elgin y Elveren, 2019); ser joven o adulto mayor (OIT, 2018); estar separa- 
do del cónyuge (Roldan y Ospino, 2009; Rivera y Benavides, 2018); contar con baja o nula formación académica (García, 2011; Lehmann y Zaiceva, 2013; Robles y Martínez, 2016; Cuevas, De la Torre y Regla, 2016; OIT, 2018); ubicarse en una zona rural (OIT, 2018); trabajar en el sector agrícola (OIT, 2018); laborar en una microempresa (Dougherty y Escobar, 2013; Baez, 2015), y contar con un empleo a tiempo parcial o temporal (Cuevas, De la Torre y Regla, 2016; OIT, 2018). En algunas de ellas se añaden otras características como son: costos por iniciar un negocio, obstáculos a la inversión extranjera (Dougherty y Escobar, 2013), tamaño de mercado, estabilidad económica (Baez, 2015) y corrupción (Dougherty y Escobar, 2013; Baez, 2015).

El interés de este documento es agrupar la mayoría de las características del empleo informal que han estudiado los autores del párrafo precedente a fin de incorporarlas en un análisis comparativo sobre los rasgos de la informalidad del mercado de trabajo en México en dos momentos del tiempo (2005 y 2020); lo que permite tener un antecedente de la situación del empleo informal antes de la pandemia originada por el virus SARSCoV-2. Si bien existe evidencia de la comparación de la informalidad en la economía mexicana en varios años; ya sea en diferentes momentos (véase Varela, Castillo y Ocegueda, 2013) o mediante datos de panel (consultar Dougherty y Escobar, 2013; Baez, 2015), comparar dos puntos de tiempo distantes (2005 y 2020) posibilita identificar cambios en la estructura del mercado del trabajo en los últimos 15 años. Por tal motivo, el objetivo de este documento es analizar las características del empleo informal en México en 2005 y 2020.

Para tal propósito, se utilizó el primer trimestre de 2005 y 2020 de la Encuesta Nacional de Ocupación y Empleo (ENOE) por tres razones: i) en 2005.I se realizó el primer levantamiento de esta encuesta; ii) 2020.I es un trimestre previo a la pandemia del Covid-19 y, por lo tanto, permite obtener datos del fenómeno de estudio en condiciones aún estables, y iii) al considerar en ambos casos al mismo trimestre, el contraste de la información se realiza sobre una base más homogénea.

A fin de alcanzar el objetivo planteado, se recurrió a un modelo de regresión logística binaria que permite examinar la relación de una variable categórica, en este caso, si el trabajador tiene un empleo informal o no, con variables independientes categóricas y/o continuas: sexo, edad, estado civil, escolaridad, localidad, tamaño de empresa, sector de la actividad económica y horas de trabajo. 
Algunos de los hallazgos indican que, en 15 años no se han presentado cambios en las características del empleo informal en México (edad, estado civil, escolaridad, localidad, tamaño de empresa, sector y horas de trabajo), excepto en la variable sexo que presentó signo diferente para ambos periodos. La variable con mayor incidencia en la informalidad es el tamaño de la empresa y la que menos es horas de trabajo. Entre las limitaciones de la investigación se encuentra los tamaños de las muestras que fueron disímiles. Aun y cuando existe literatura que da soporte a la comparación de modelos de regresión logística binaria, los resultados deben tomarse con mesura.

El documento se divide en siete secciones. La primera, versa sobre el origen y definición del concepto de empleo informal en el marco de la economía informal. La segunda, se relaciona con una revisión de las principales perspectivas teóricas que analizan la economía informal: dualista, estructuralista, legalista y voluntarista. La tercera, aborda los determinantes de la informalidad con base en la revisión de la literatura. La cuarta, analiza el empleo informal en América Latina y México. La quinta, describe la metodología asociada con el modelo de regresión logística binaria, con datos del INEGI, en específico, de la ENOE. La sexta, muestra los resultados y, finalmente, se presentan las conclusiones.

\section{ORIGEN DE LA DEFINICIÓN DE EMPLEO INFORMAL}

Neffa (2008) establece que la definición de trabajo o empleo informal tiene sus antecedentes en las aportaciones de Lewis (1954) cuando analizó las economías en vías de desarrollo e identificó dos sectores. Por un lado, el tradicional, relacionado con las actividades primarias y, por otro, el moderno, asociado con las actividades de la transformación y servicios característicos de las urbes. El exceso de oferta laboral en las zonas rurales (desempleada o subempleada) originaba las migraciones hacia las ciudades. Esta fuerza de trabajo inmigrante aceptaba trabajos informales para poder subsistir. Una de las pretensiones de Lewis (1954) era conformar un análisis diferente en los países en los que las suposiciones neoclásicas y keynesianas no concordaban. Según este autor, existía un desempleo disfrazado representado por trabajadores ubicados en los muelles, personas que se ofrecían a cargar las maletas, los jardineros o bien, el comercio minorista, pero que percibían una paga baja.

Por otro lado, algunos estudiosos del mercado de trabajo (Chen, 2005; De la Garza, 2011) consideran que el precedente del empleo informal aparece por primera vez en estudios multidisciplinarios realizados en países en 
desarrollo para explicar el desempleo que prevalecía en estas economías, en contraste con la época dorada del trabajo de Europa y Estados Unidos de los años cincuenta y sesenta del siglo XX. A inicios de la década de los setenta, se presentan investigaciones sobre el mercado de trabajo en Ghana y Kenia. En el primer caso, se emplea por primera ocasión el término sector informal (Chen, 2005; Chen, 2012) y se le asocia con el trabajo por cuenta propia. Keith Hart (1973) estudió a un grupo de ghaneses analfabetas que migraban del norte rural a las áreas urbanas del sur e identificó a la informalidad como un mecanismo para aumentar los ingresos del subproletariado urbano, aspecto que la estructura formal no permitía. Asimismo, reconoció una serie de elementos que detonaban la informalidad: inflación, salarios inadecuados y mayores requisitos a la mano de obra urbana. En cuanto a la investigación en Kenia, se empleó el término sector informal para referirse a las actividades económicas de pequeña escala y no registradas (Chen, 2005). Es decir, el concepto de empleo informal tiene sus orígenes en estudios llevados a cabo en economías en desarrollo que definen por primera vez al sector informal.

Aunque la informalidad se observa, principalmente, en economías en desarrollo, también se encuentra presente en países desarrollados, por ejemplo, en 2016, Australia, Canadá, Estados Unidos, Francia, Italia, entre otros, contaron con niveles de empleo informal menores a 20 por ciento del total de su población ocupada. En contraste, economías como: Mauritania, Nigeria, Somalia, Etiopía o Afganistán presentaron porcentajes de 90 por ciento y más (OIT, 2018: 13).

Retomando la evolución del concepto de empleo informal y su antecedente en el sector informal, es necesario destacar que la definición de este último, por parte de la International Labour Organization (ILO por sus siglas en inglés, 1993), en la década de los noventa, hacía referencia a pequeñas unidades (empresas) que eran variadas tanto en las actividades como en las formas de operar y que, de alguna forma, no correspondían al sector formal. De acuerdo con la definición de la ILO (1993), se puede rescatar la unidad principal de análisis: las empresas productoras de bienes o servicios, que por lo general, operan con bajo nivel de organización, con poca o ninguna división entre los factores de producción (trabajo y capital) y en una escala más pequeña. En el caso de las relaciones laborales que se observan dentro de ellas, se basan, principalmente, en el empleo casual, el parentesco o las relaciones sociales en lugar de acuerdos contractuales con garantías formales. Esto es, la descripción de informalidad está basada en 
la empresa y su tamaño; por lo tanto, los trabajadores que se ubican en ella conformarían la mano de obra del sector informal.

Más tarde, la OIT con base en críticas realizadas a la medición del empleo en el sector informal (Hussmanns, 2004) y en la resolución de la Nonagésima Sesión de la Conferencia Internacional de Trabajo (Vanek, Chen, Carré, Heintz and Hussmanns, 2014), incorpora el concepto de empleo informal que forma parte de un fenómeno más amplio: economía informal. La referida, de acuerdo con la ILO (2002: 2), contempla tanto a las empresas como a las actividades económicas de los trabajadores que, en la ley o en la práctica, no están cubiertas o no están suficientemente cubiertas por acuerdos formales, es decir, sus actividades están operando fuera del alcance formal. De ahí que la economía informal incluye a ambos fenómenos: al sector informal (empresas que operan fuera del alcance de la ley) y al empleo informal. Al primero porque, desde el enfoque de la unidad productiva, ahí se pueden hallar figuras como: trabajadores por cuenta propia y empleadores; y al segundo, porque al tomar en cuenta las condiciones laborales informales se ubicarán categorías de trabajadores subordinados remunerados y no remunerados (INEGI, 2014). En otras palabras, la economía informal, en contraste con el concepto de sector informal, permite llenar algunos vacíos de conceptualización y medición que había dejado de lado el segundo. De este modo, no solo se contempla el trabajo que se realiza en las unidades económicas informales, además, se incluyen ocupaciones en condiciones de informalidad fuera del sector informal como son: autoempleo en la agricultura; trabajadores no remunerados; trabajadores remunerados, pero no protegidos; trabajo en los hogares remunerado y tampoco protegido, entre otros (INEGI, 2014).

En lo que respecta al tema de análisis de este documento, la OIT establece que

para que el puesto de trabajo de un empleado se considere informal, la relación de trabajo no deberá estar, ni legalmente ni en la práctica, sujeta a la legislación laboral nacional, a impuestos sobre las ganancias, a protección social o al derecho a ciertas prestaciones relacionadas con el empleo (OIT, 2018: 10).

Como se puede observar, la evolución de los estudios que refieren a la informalidad comenzó con el concepto de sector informal hasta llegar al de economía y empleo informales; no obstante, es de esperarse que surjan nuevos conceptos y formas más precisas de medición conforme las actividades económicas vayan evolucionando. Cabe aclarar que, para esta investigación, el empleo informal se entenderá como aquél que no se ubica 
bajo el marco legal e institucional, en otras palabras, es el empleo carente de protección laboral por no situarse bajo el amparo legal que ofrece la formalidad. Por lo tanto, la problemática que representa el ubicarse en un empleo en tales condiciones está relacionada con: “(...) falta de identidad jurídica; condiciones de trabajo deficientes; falta de afiliación al sistema de protección social; mayor incidencia de accidentes y enfermedades laborales; y limitada libertad de asociación" (OIT, 2015a: 20). Aunado a lo anterior, aunque no existe una relación directa entre el empleo informal y ser pobre, existe un porcentaje mayor de la población ocupada en la informalidad en situación de pobreza respecto de la que trabaja en la formalidad (ILO, 2002; OIT, 2018). Lo anterior, probablemente está asociado con el bajo nivel de ingreso respecto de los trabajadores en situación de formalidad (OIT, 2017), así como una nula presencia de prestaciones laborales que hace que el trabajador informal deba utilizar parte de su ingreso para cubrir necesidades como la protección social. De acuerdo con lo anterior, se confirma la necesidad de llevar a cabo un análisis del empleo informal por las implicaciones económicas y sociales que conlleva no solo para la economía, sino para su población.

\section{Perspectivas teóricas sobre la INFORMALIDAd}

Existen diversas perspectivas que analizan la informalidad, así como sus clasificaciones. Chen (2012) identifica cuatro corrientes de pensamiento económico-social que estudian a la economía informal: dualista, estructuralista, legalista y voluntarista. Mientras La Porta y Shleifer (2008) presentan otra clasificación, de acuerdo con el papel que juegan las empresas no oficiales (informales) en el desarrollo: dualista romántico y parásito. La diferencia de estas ordenaciones estriba en la división que hace Chen (2012) porque separa la dualista (que proponen Porta y Schleifer, 2008) y conforma una más, la estructuralista.

Iniciando con la descripción de la visión dualista, los sectores formal e informal no se encuentran relacionados, o bien, presentan poca conexión (Chen, 2012). De hecho, las empresas informales (sector tradicional) no representan una amenaza para las formales (sector moderno) debido a la ineficiencia de las primeras (baja productividad), además, en la mayoría de los casos, operan en diferentes mercados para clientes disímiles (La Porta y Shleifer, 2008). El sector informal, se constituye como el sector con menos beneficios debido al desequilibrio entre: a) crecimiento poblacional y empleo en la industria, y b) las destrezas de la fuerza de trabajo y la estructura de las economías modernas (Chen, 2012). Otra de sus características versa 
sobre la mano de obra que se relaciona con éste, donde el empleador realiza las funciones de trabajador $y$, de forma adicional, da empleo a familiares (sin remuneración) y a otros individuos sin contrato, por lo que la falta de protección laboral es otro rasgo de la informalidad (Tokman, 2008).

Para la versión estructuralista, lo formal y lo informal están estrechamente asociados y es el propio sistema capitalista el que fomenta la informalidad (microempresas) puesto que las empresas formales buscan reducir costos, principalmente de la mano de obra, así como incrementar su competitividad; resistir el poder de los sindicatos, al igual que la reglamentación que imponen los Estados, la competencia internacional y la reestructuración industrial (Chen, 2012). En este sentido, los empleadores del sector formal o moderno contratan trabajadores del sector informal para disminuir los costos que conlleva la formalidad (seguridad social o protección contra despidos arbitrarios) y este vínculo se puede realizar mediante dos mecanismos: a) trabajo eventual y b) subcontratación de empresas informales (Portes y Benton, 1987).

En el enfoque legalista (Chen, 2012), la visión romántica (La Porta y Shleifer, 2008), o bien, llamada neoclásica, la economía informal está conformada por los microempresarios valientes. Estos deciden estar en la informalidad para eludir aspectos relacionados con el registro formal como: esfuerzo, costos y tiempo. Lo anterior, se debe a que el sistema de la formalidad cuenta con elementos desfavorables, lo que obliga a los trabajadores independientes a ubicarse en lo informal (Chen, 2012), con lo cual se contradice que sea un asunto de vocación (De Soto, 1995). Una posible solución, sería disminuir las barreras para impulsar la formalidad y, a su vez, el crecimiento económico (La Porta y Shleifer, 2008).

En la visión voluntarista (Chen, 2012) o parásito (La Porta y Shleifer, 2008), la informalidad existe porque los empresarios (racionales), una vez que realizaron un análisis de costo-beneficio, eluden las regulaciones, los impuestos y los costos de transacción que emanan del actuar del Estado (Chen, 2012); por lo que se ubican en una situación de ventaja frente a las empresas formales, pero de forma desleal y, para evitar esta condición, se sugiere que los negocios informales se conviertan en formales, lo cual, también aumentaría la base gravable (Chen, 2012). Es importante señalar que los trabajadores poco calificados también realizan un análisis de costo-beneficio por medio del cual no encuentran diferencia significativa entre estar en un empleo formal (salario bajo y prestaciones) y uno formal; puesto que los programas universales les brindan una oportunidad 
de protección social (Perry, Maloney, Arias, Fajnzylber, Mason y Saavedra-Chanduvi, 2007).

Con base en lo expuesto, se puede establecer que las diversas corrientes proporcionan un mapa general del empleo informal, a través de las particularidades que cada una señala. Los trabajadores informales, se conforman por empleadores con funciones de trabajador, trabajadores familiares (sin remuneración) y otros empleados sin contrato ni prestaciones laborales (visión dualista). Además, se asocian con el trabajo eventual (visión estructuralista), las microempresas (visiones estructuralista y legalista) y unidades productivas que al eludir regulaciones e impuestos se espera que los trabajadores no estén registrados ante el fisco, por lo que se confirma la ausencia de protección laboral y, al mismo tiempo, la falta de calificación es otra peculiaridad del empleo informal (visión voluntarista o parásito).

Es importante señalar que esta clasificación de las teorías deja fuera algunas otras perspectivas de la informalidad que escapan de este análisis. No obstante, sobresale la neomarxista que establece que las actividades económicas que se consideran informales son producto de las formas de producción características del capitalismo industrial de hace dos siglos (Dore-Cabral, 1995). En virtud de ello, Portes (1995), de origen estructuralista, considera que lo que se conoce hoy como empleo informal se asocia con los rasgos del empleo del siglo XIX; por lo tanto, lo nuevo no es la informalidad laboral, más bien lo es el empleo formal, y lo que hace el capitalismo es contrarrestar los logros de la clase trabajadora, mediante la modernización de modos de producción anteriores, pero auxiliándose, también, de su internacionalización: el empleo informal favorece a las empresas mediante la subcontratación de la producción.

En la mayoría de los casos, el empleo informal es una forma de sobrevivencia, más no de elección. Aun así, algunos de sus rasgos están asociados a las condiciones de trabajo inapropiadas e inseguras y los bajos ingresos generados por la actividad económica. Asimismo, la falta de seguridad social, así como los trabajadores por cuenta propia y los trabajadores familiares auxiliares son peculiaridades que de inmediato se asocian con el empleo informal. Los trabajadores por cuenta propia también se vinculan con la informalidad: más de 80 por ciento, a nivel internacional, es informal (OIT, 2018: 17), y los trabajadores clasificados como familiares auxiliares son considerados informales desde el punto de vista estadístico (OIT, 2018). Para profundizar en las características de la población ocupada en este tipo de empleos, algunas investigaciones permiten identificar algunos determinantes, los cuales se señalan a continuación. 


\section{DETERMINANTES DE LA INFORMALIDAD}

Una de las primeras características asociadas con la informalidad es el sexo (Cuevas, De la Torre y Regla, 2016; OIT, 2018). De acuerdo con la OIT (2018), tanto en países emergentes, en desarrollo y economías desarrolladas, son los hombres quienes evidencian mayor porcentaje en empleos informales respecto a las mujeres. Lehmann y Zaiceva (2013), en un análisis que realizaron acerca de la informalidad en Rusia, mencionan que las mujeres trabajadoras, durante el periodo 2007-2013, presentaron una menor incidencia en el empleo informal respecto de los hombres. Sin embargo, en cuanto a la probabilidad de ubicarse en un empleo informal, en un estudio sobre el impacto de las instituciones y la política en la economía informal para países en desarrollo, Rei y Bhattacharya (2008) hallaron una mayor probabilidad en las mujeres una vez que tienen la oportunidad de participar en alguna actividad económica. De hecho, son ellas quienes perciben salarios más bajos generando mayor productividad por cada dólar pagado (Elgin y Elveren, 2019), asimismo, se ubican en actividades de mayor vulnerabilidad laboral como el caso de las trabajadoras del hogar o a domicilio (OIT, 2018). No obstante, de acuerdo con Elgin y Elveren (2019), en un estudio sobre informalidad, inequidad y feminización del trabajo, establecen que las mujeres, de alguna forma, se ven beneficiadas por la informalidad, ya que les permite equilibrar las actividades laborales con las del hogar.

Otro rasgo de la informalidad es la edad. Los empleos informales se vinculan con los jóvenes (15-24) y los adultos mayores (más de 65), de hecho, en las economías emergentes y en desarrollo, es el mecanismo más probable mediante el cual la población joven accede a un trabajo. En América Latina y el Caribe, 60 por ciento de los trabajos nuevos para los jóvenes son informales; sin embargo, los adultos mayores presentan mayor probabilidad de encontrase en este tipo de empleos respecto a los jóvenes, indistintamente en países desarrollados y en desarrollo (OIT, 2018).

En cuanto al sector de la actividad económica, el agrícola, a nivel mundial, cuenta con mayor número de empleados informales (OIT, 2018). Asimismo, el sector servicios aglutina un porcentaje elevado de empleo informal, por ejemplo, para la economía mexicana, más de 50 por ciento de su población ocupada se ubica en el sector terciario (INEGI, 2020a).

El estado conyugal también es una característica sociodemográfica de la informalidad. Rivera y Benavides (2018), en un estudio sobre la informalidad en Bogotá, hallaron que las personas casadas están menos articuladas al empleo informal. Roldan y Ospino (2009), en un análisis de 
la informalidad en áreas metropolitanas de Colombia: Barranquilla, Cartagena y Montería, encontraron que el estado civil y su incidencia en la informalidad es diferente en estas tres áreas de estudio. En Cartagena no hubo disimilitudes en la probabilidad de ubicarse en empleo informal entre ser soltero y casado; lo mismo ocurrió en Montería, pero al considerar la Seguridad Social dentro de la definición de informalidad, ser casado tiene menor probabilidad de ser informal, y en Barranquilla, efectivamente, ser casado disminuye la probabilidad de ubicarse en empleo informal. Robles y Martínez (2018) en un estudio realizado en México, encontraron diferencias regionales respecto al estado civil, concretamente, estar casado o soltero, y su vínculo con la informalidad. Lo anterior se explica porque algunas mujeres casadas acceden al empleo informal para atender las labores domésticas y el cuidado de los niños.

Un factor más asociado con la informalidad es el nivel educativo: mayor nivel de educación se vincula con la formalidad (Lehmann y Zaiceva, 2013; Robles y Martínez, 2015; Cuevas, De la Torre y Regla, 2016; OIT, 2018). Por su parte, García (2011) al estudiar determinantes macro y efectos locales de la informalidad laboral en Colombia, encontró que la informalidad disminuye en cuatro por ciento al incrementarse un año de instrucción en la población trabajadora, advirtiendo sobre la importancia de las políticas públicas para mejorar las condiciones de empleo. De la misma manera, la localización del trabajador en zona rural es un rasgo de la informalidad. De acuerdo con la OIT (2018) existe dos veces la probabilidad de ubicarse en un trabajo informal cuando la persona vive en una zona rural respecto de quien vive en zona urbana.

Lo mismo ocurre con el tamaño de la empresa: son las microempresas como unidades productivas las que aglutinan el mayor porcentaje de empleos informales. Baez (2015), en un estudio sobre determinantes de la informalidad, pero desde la perspectiva de la demanda del trabajo (empresas), establece que el mayor número de empresas informales está conformado por las de menor tamaño, es más, el porcentaje de trabajadores en las microempresas se puede considerar como una variable proxy de la informalidad. Dougherty y Escobar (2013), en un análisis sobre los determinantes de la informalidad en los estados de México, encuentran como prevalente la presencia de microempresas, además, consideran que, si se reducen los costos para crear una empresa, siempre y cuando fomenten el tamaño pequeño, mediano y grande, entonces la informalidad disminuirá.

Otro factor que está relacionado con la informalidad, es el tiempo de trabajo, es decir, las horas destinadas a la actividad laboral. Los trabajos 
temporales y a tiempo parcial (menos de 35 horas semanales) son un ejemplo del tipo de trabajos con número reducido de horas (OIT, 2018). Cuevas, De la Torre y Regla (2016) en un estudio sobre las características y determinantes de la informalidad laboral en México, encontraron que el trabajador formal trabaja más horas en comparación con el informal porque la unidad productiva, para la cual labora, establece horas fijas (40 a 48 horas), mientras que la jornada es más flexible para el caso de los segundos.

Como se puede observar, son diversos los rasgos del empleo informal cuya importancia de estudio se encuentra en la situación de bajos niveles de ingreso y desprotección social. De ahí la relevancia de analizar sus características para el caso mexicano, lo cual se describe a continuación.

\section{Empleo informal en América Latina y MéXico}

La informalidad en América Latina tiene sus orígenes en la segunda mitad del siglo pasado con el proceso migratorio campo-ciudad relacionado a su vez con la industrialización de la región. Desde una perspectiva dualista, de acuerdo con Tokman (1982) el sector moderno no fue capaz de absorber el exceso de mano de obra proveniente de las zonas rurales, de ahí que se comenzó a conformar un sector informal. Al mismo tiempo, la tasa de crecimiento poblacional durante el periodo 1960-1965 fue de los más altos para el continente (2.9 por ciento promedio anual), por lo que el mercado de trabajo se transformó no solo por la migración interna, sino por el aumento de la población en edad de trabajar y la mayor intervención de la mujer en el mercado de trabajo que durante el periodo 1970-1980 presentó la participación más acelerada: la tasa de crecimiento anual de la mano de obra femenina fue de 4.7 por ciento contra 2.8 por ciento de la masculina (Infante y Klein, 1991: 129). Paralelamente, el sector servicios se convirtió en la principal fuente de absorción del personal ocupado, destacando mujeres y jóvenes como su principal mano de obra. Sin embargo, Infante y Klein (1991) coinciden con Tokman (1982): persistió el sector tradicional y el moderno no tuvo la capacidad para captar la mano de obra proveniente del campo y del aumento poblacional.

A lo largo de la década de los noventa, el sector terciario de la actividad económica continuó su expansión y, desde los ochenta, ya se observaba una concentración de la mayor parte de la informalidad en este sector. Destacan las microempresas como principal fuente generadora de empleos, aunque son los trabajos por cuenta propia los que presentaron tasas más altas de empleo urbano. De hecho, la mayor parte del empleo de la región se originó en el sector informal "entre 1990 y 1996 (...) el sector informal 
aumentó su participación en el empleo no agrícola de 51.6 por ciento a 57.4 por ciento" (Weller, 1998: 15).

A pesar de la apertura comercial de los años noventa y el cambio en el modelo de acumulación, la informalidad perdura en las economías latinoamericanas. A inicios el siglo XXI, de acuerdo con datos de Tokman (2004: 184), 46.6 por ciento del empleo urbano en la región se encontraba en el sector informal; en contraste con 30.6 por ciento en 1950. De acuerdo con la OIT (2016), durante el periodo 2009-2013 el empleo informal no agrícola en América Latina disminuyó de 50.1 a 46.8 por ciento. Si se observa el dato que presenta la OIT (2016) para 2013, está por encima de lo que reporta Tokman (2004) a inicios del siglo XXI, pero lo anterior está relacionado con la medición del concepto: los datos de Tokman cuantifican al sector y no al empleo informal (OIT, 2016). De lo anterior, se desprende la complejidad de analizar la informalidad a lo largo del tiempo; no obstante, lo que refleja la información anterior es que durante los últimos años el tamaño de la informalidad (cuantificada como empleo informal) ha ido disminuyendo, pero persiste y, de acuerdo con datos de la Comisión Económica para América Latina y el Caribe (CEPAL, 2019), el bajo ritmo de crecimiento de las economías latinoamericanas y la consecuente escasa generación de empleo asalariado, puede provocar un aumento de la informalidad laboral.

De acuerdo con la OIT (2018), se estima que más de 60 por ciento de la población ocupada a nivel internacional se ubica en la economía informal y, aunque esta situación se puede observar en todas las economías del mundo, más de 90 por ciento de la población en mención se encuentra en las economías emergentes y en desarrollo (OIT, 2018). Para el caso de América Latina, considerando el empleo informal agrícola, el porcentaje es de 53.1 por ciento; sin embargo, las diferencias entre economías son notables: en Uruguay esta población no representa ni siquiera una tercera parte del empleo total, en contraste con economías centroamericanas que exhiben porcentajes cercanos a 80 por ciento de su población ocupada en la informalidad (Figura 1).

De acuerdo con datos de INEGI (2020a), la tasa de informalidad laboral ha disminuido a lo largo del tiempo: después de haber rebasado 60 por ciento a nivel nacional, en el primer trimestre de 2020 se ubica en 56.08 por ciento (Figura 2).

Sin embargo, a pesar de encontrarse en niveles inferiores a los alcanzados en 2009, en comparación con las estadísticas mundiales, el número de trabajos informales siguen siendo elevado (OECD, 2017). 


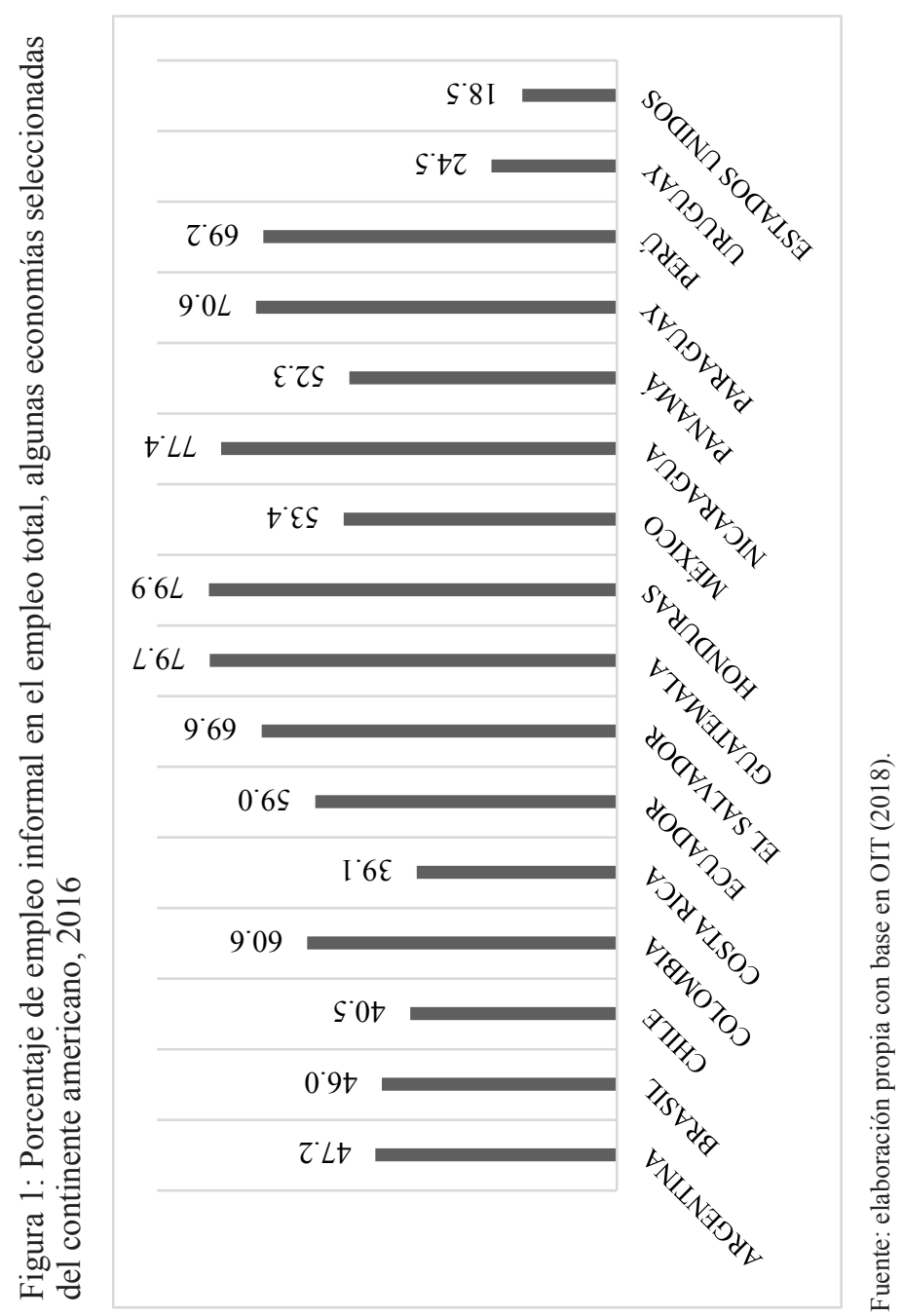


Características del empleo informal en México, 2005 y 2020 / W. OVANDO ALDANA et al.

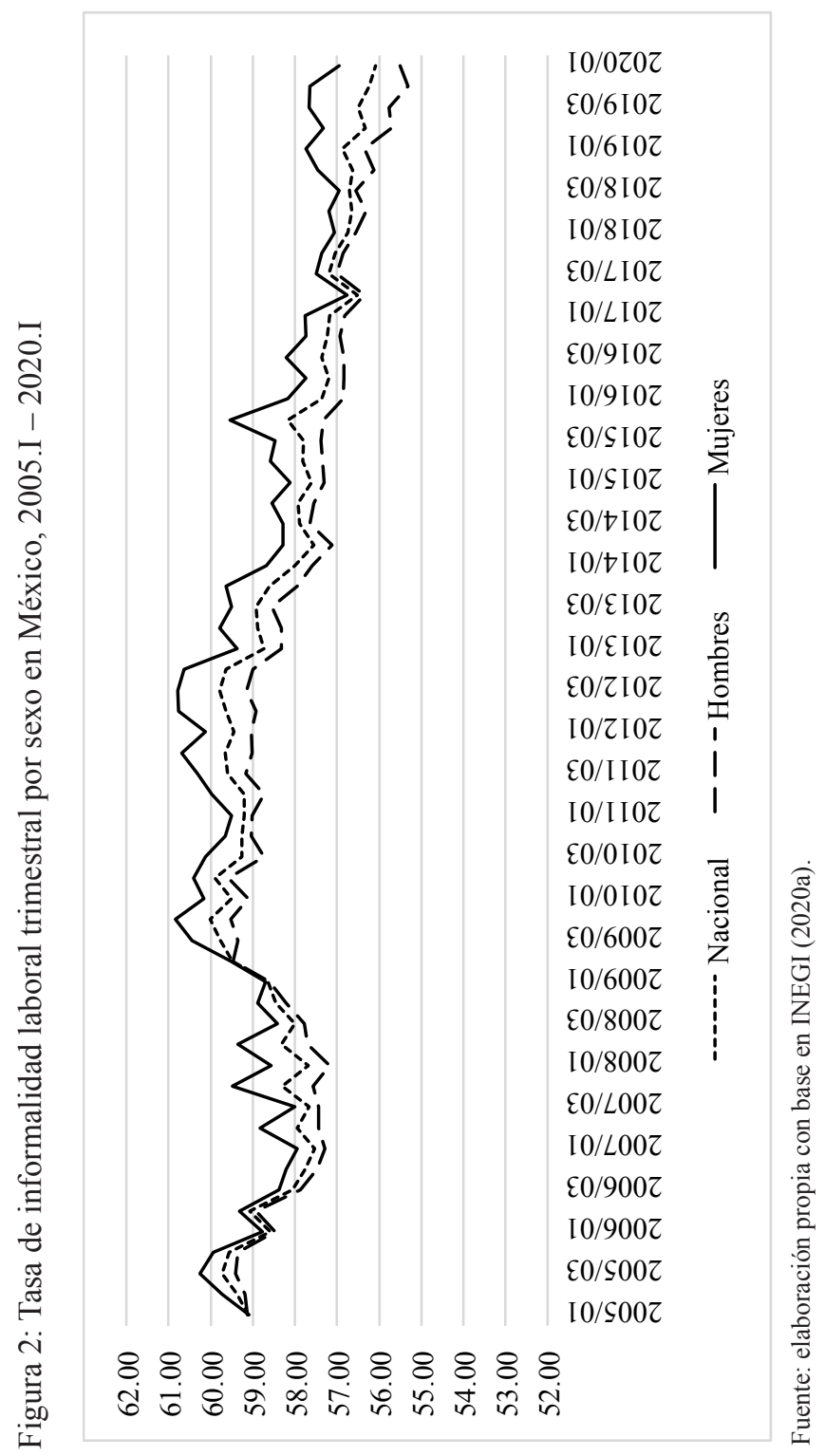


La tasa de informalidad laboral representa el porcentaje de la ocupación informal que no cuenta con garantía de seguridad social básica (servicios de salud) ni laboral (falta de contrato) (si la unidad productiva en la que labora no está registrada) (INEGI, 2014: 27); por lo que, en México, más de la mitad de la población ocupada total se encuentra en "situación de vulnerabilidad para hacer valer las garantías laborales elementales", situación que se acentúa en el caso de las mujeres. A pesar de que los hombres son mayoría en los empleos informales (59.88 por ciento versus 40.12 por ciento para las mujeres) (INEGI, 2020a), al analizar la tasa de informalidad ocurre lo contrario: ellas se ubican por encima de la media nacional, agudizándose su situación en periodos en los que este indicador es alto a nivel nacional (Figura 2).

Una de las principales causas de la informalidad en México está asociada con el bajo ritmo de crecimiento económico que no ha permitido asimilar el aumento de la oferta laboral (OIT, 2014). De hecho, desde los años ochenta la economía presenta tasas de crecimiento bajas, lo mismo que la de desempleo (Loría, Aupart y Salas, 2016). En otras palabras, la informalidad ha permitido amortiguar la desocupación (OIT, 2014; Cuevas, De la Torre y Regla, 2016; Loría, Aupart y Salas, 2016); no obstante, ha condicionado, a través de la disminución de la productividad total de los factores, el crecimiento de largo plazo (Loría, Aupart y Salas, 2016).

Algunos estudios sobre el mercado de trabajo en México indican que la informalidad presenta ciertas particularidades: escolaridad, sexo, edad, ubicación territorial, entre otras (Dougherty y Escobar, 2013; Varela, Castillo y Ocegueda, 2013; Baez, 2015; Robles y Martínez, 2018; Cuevas, De la Torre y Regla, 2016). Varela, Castillo y Ocegueda (2013: 135), mediante un análisis discriminante sobre dos grupos de jefes de hogar, con empleo formal y otros con informal, en tres periodos de tiempo $(2005,2009$ y 2012), concluyeron que "el contrato laboral, la ocupación por tamaño de establecimiento, los años de escolaridad, el tipo de localidad y el proceso de búsqueda de un nuevo empleo" permiten diferenciar a estos dos grupos de trabajadores. Asimismo, identifican a la variable escolaridad cuyo coeficiente presentó mayor cambio de 2009 y 2012 respecto de 2005 porque se incrementó su poder discriminante. Por su parte, Robles y Martínez (2018), a través de un modelo econométrico probit, con datos de la Encuesta Nacional de Ingresos y Gastos de los Hogares de 2012, encontraron que los trabajadores seleccionan estar en la informalidad dependiendo de la calidad de los servicios de algunas instituciones de seguridad social. Cuevas, De la Torre y Regla (2016) también emplearon un modelo probit, con 
datos de la ENOE de 2015, para analizar, en este caso, las características y determinantes de la informalidad laboral en México. Hallaron que la informalidad se vincula con: bajos niveles de educación; ubicación en regiones marginadas; ser mujer, pero sobre todo si se cuenta con hijos pequeños; ser joven, o bien, ser adulto mayor.

Por otra parte, Dougherty y Escobar (2013) y Baez (2015) realizaron estudios incluyendo un análisis estatal con datos de panel. Para el primer caso, los autores, con una serie de datos (2005-2010) identificaron múltiples factores que determinan las desigualdades del empleo informal en las entidades federativas: ingreso percápita, habilidades de la mano de obra, disimilitudes en el predominio de microempresas, los costos por iniciar un negocio, limitantes a la inversión extranjera y la corrupción. En el segundo caso, Baez (2015) centró su análisis desde la demanda de trabajo (empresas) en una investigación sobre la informalidad de las microempresas en las entidades mexicanas, en la cual analizó la asociación de variables económicas y no económicas con la informalidad. Con ello, encontró que variables como: tamaño de mercado y estabilidad económica, para el primer caso, así como corrupción —al igual que Dougherty y Escobar (2013) - y educación, para el segundo, son determinantes del empleo informal.

Con base en la literatura revisada, existen pocos trabajos en cuanto a la comparación de las características del empleo informal en momentos del tiempo distantes. Lo anterior, permitiría identificar cambios en la estructura del mercado de trabajo, en específico, de la informalidad. Ya se ha dicho que desde los años ochenta se presentaron bajas tasas de crecimiento económico y que la informalidad ha sido la válvula de escape para el desempleo. No obstante, sería importante identificar si las particularidades del empleo informal han variado en dos puntos distantes del tiempo.

\section{Metodología}

La forma en la que se identificó la relación entre las variables (empleo informal y sus características) es a través de un modelo de regresión logística binaria. Lo que se busca en un modelo como éste es identificar la relación entre una variable denominada latente $\left(Y^{*}\right)$ y las variables exógenas (independientes). Se denomina variable latente a la variable modelizada (no observada) que en una regresión logística estará en función de la relación de la variable dicótoma $Y$ (observada) y las variables independientes (Escobar, Fernández y Bernardi, 2012).

La variable $Y$ toma solo dos valores: 0 y 1 y existen tres objetivos en un modelo de regresión logística (Salas, 1996): i) verificar si existe o no 
relación entre la(s) variable(s) independiente(s) y una variable dependiente dicótoma; ii) medir el signo de la relación, y iii) estimar la probabilidad de que suceda o no un evento expresado como $Y=1$. La formalización de esta relación se observa en la siguiente ecuación (Escobar, Fernández y Bernardi, 2012):

$$
\mathrm{y}^{*}=\beta_{0}+\beta_{1} \mathrm{x}_{\mathrm{i} 1}+\ldots+\beta_{\mathrm{k}} \mathrm{x}_{\mathrm{ik}}+\varepsilon_{\mathrm{i}}=\mathrm{x}_{\mathrm{i}} \beta+\varepsilon_{\mathrm{i}}
$$

Donde:

$\mathrm{y}^{*}=$ variable latente

$\beta_{0}$ es la constante

$\beta_{\mathrm{k}}$ coeficientes asociados a cada una de las variables independientes $(x)$

$\varepsilon_{\mathrm{i}}$ error aleatorio

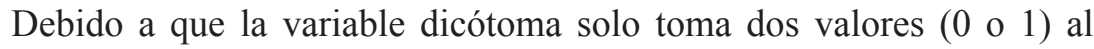
utilizar un modelo de regresión lineal, los valores que tomará la variable dependiente estarán fuera del rango 0 y 1 , es decir, pueden ser menores a 0 o mayores a 1, para evitar estos resultados, las probabilidades se pueden transformar en razones al dividir la probabilidad de ocurrencia del evento entre la no ocurrencia. Al final de un proceso algebraico, se tiene la ecuación de la regresión logística:

$$
\ln \frac{\operatorname{Pr}(y=1 \mid x)}{1-\operatorname{Pr}(y=1 \mid x)}=\ln \Omega(x)=\boldsymbol{x} \boldsymbol{\beta} \ldots
$$

Se llama logit al logaritmo neperiano de la razón, y es, precisamente, la variable $Y$ de la ecuación de la regresión logística. Para que la regresión pueda ser interpretada se transforma la ecuación en forma de coeficientes, por lo tanto, se elimina el logaritmo para que se obtengan razones (odds ratio) y los coeficientes representen la variación que las $X$ generan en la razón de ocurrencia de un evento:

$\Omega(x)=\frac{\operatorname{Pr}(y=1 \mid x)}{1-\operatorname{Pr}(y=1 \mid x)}=\exp (\boldsymbol{x} \boldsymbol{\beta})=\exp \left(\beta_{0}+\beta_{1} x_{i 1}+\cdots+\beta_{k} x_{i k}\right)=w_{0} w_{1}^{x 1} \ldots w_{k}^{x k} \ldots$

Donde $w_{k}=\exp \left(\beta_{k}\right)$ : ahora los coeficientes obtenidos $\left(w_{i}\right)$ mostrarán cómo varía la razón de la variable $Y$ cuando una variable $X$ cambia en una unidad. 
Dada la facilidad de la interpretación de la regresión logística binaria mediante el cálculo de los odds ratio, es que se ha seleccionado este tipo de modelo por encima del denominado probit, aun y cuando este último ha sido de mayor uso en los estudios de informalidad en México. Asimismo, ambos modelos en la práctica proporcionan ajustes similares, por lo que, si uno ajusta bien, el otro también lo hará (Agresti, 2007). En virtud de ello, se esperan resultados similares con ambos tipos de modelos.

\section{VARIABLES}

La fuente de información es la Encuesta Nacional de Ocupación y Empleo (ENOE) que emite el INEGI. La referida es una encuesta que recaba información sobre el mercado laboral en México a nivel nacional, estatal, así como de 39 ciudades y respecto de cuatro tamaños de localidad. Ofrece datos mensuales y trimestrales sobre temas como: informalidad laboral, subocupación, fuerza de trabajo y desocupación (INEGI, 2020b).

Para este caso se tomó el primer trimestre de 2005 y 2020 para ser comparables, además, por ser la información más reciente con la que cuenta el INEGI para 2020 que corresponde a un trimestre previo a la pandemia del Covid-19. Lo anterior, permite analizar el mercado de trabajo antes de la ocurrencia de un fenómeno externo que hasta el momento ha tenido fuertes repercusiones en el número y calidad de empleos en el mundo.

Se decidió estimar el modelo de regresión logística binaria en dos momentos, como ya se ha mencionado en otras secciones: 2005.I y 2020.I. De acuerdo con Buis (2017) es posible realizar la comparación de odds ratios entre diferentes grupos (incluyendo muestras comparadas y puntos en el tiempo). Lo anterior, porque una comparación de las razones de probabilidades entre los grupos facilita una descripción precisa de la diferencia en los efectos entre estos grupos. Kuha y Mills (2020) sugieren que es posible la comparación si la estimación cumple los supuestos requeridos y, si, además, las variables $X$ y $Y$ se determinan de igual forma en ambos grupos, es decir, tanto la forma de medida como la escala empleada es la misma. Adicionalmente, es importante que las preguntas de investigación, así como la interpretación de resultados se dirijan hacia la $Y$ binaria observada más que a la variable latente $Y$.

Las variables consideradas, con base en la revisión de literatura, se definieron en la Tabla 1. Es preciso puntualizar que las categorías que presenta la ENOE, para cada variable, fueron adecuadas para este estudio (columna 3 de la Tabla 1); eliminando los datos no especificados o aquellos que establecieran el desconocimiento de la clasificación por parte del encues- 
tado. Para el caso de las variables seleccionadas es importante señalar que se tomó como población objetivo a los ocupados y, en el caso del empleo informal, se recuperó el mnemónico emp_ppal de la ENOE que permite identificar la clasificación de los empleos formales e informales. Se contó con una muestra de 151,920 y 163,776 encuestados para ambos periodos (2005.I y 2020.I), respectivamente, de los cuales 37.22 y 41.19 por ciento fueron mujeres, así como 62.78 y 58.81 por ciento fueron hombres recíprocamente, es decir, más de la mitad de los encuestados con empleo informal fueron hombres, excediendo el caso para 2005.I. De ahí que en el caso de la variable sexo, aun y cuando las mujeres son quienes más están relacionadas con el empleo informal, se haya colocado como 0 a las mujeres y 1 a los hombres. De igual forma, se consideraron cuatro variables categóricas más (estado civil, localidad, tamaño de empresa y sector) y tres variables continuas (edad, escolaridad y horas de trabajo).

Las variables como "Cuenta o no con seguridad social" o "Situación en el empleo (cuenta propia)" no fueron incluidas en el modelo porque el INEGI ya considera estas variables para calcular el empleo informal. Lo mismo ocurre con el nivel de ingreso, ya son informales quienes no perciben ingreso (por ejemplo). En otras palabras, se buscaron variables que se asociaran con la variable $Y$ (empleo informal) sin que estuvieran contenidas en la definición estadística del INEGI. Cabe mencionar que para la estimación del modelo se empleó el paquete estadístico STATA versión 14.

\section{Análisis de Resultados}

\section{Algunas características del empleo informal en México}

Antes de estimar el modelo, se consideró pertinente analizar algunos rasgos de la informalidad en el mercado de trabajo mexicano. Una forma de analizar cambios en el empleo informal durante los últimos 15 años es a través de los indicadores estratégicos que ofrece INEGI cada trimestre. Como se observa en la Tabla 2, en grupos de edad, en el periodo de tiempo que se estudia, la informalidad comienza a ganar terreno en las edades de 45 a 64 años, aún y cuando los porcentajes más altos se hallan en los grupos etarios de 15 a 44 años que aglutinan más de 60 por ciento del total de la informalidad. 
Tabla 1: Variables del modelo de regresión logística binaria en el análisis del empleo informal en México, 2005.I y 2020.I

\begin{tabular}{|c|c|c|c|c|}
\hline \multicolumn{5}{|c|}{ Variable dependiente: Empleo formal = 0 y Empleo informal $=1$} \\
\hline $\begin{array}{l}\text { Variable } \\
\text { independiente }\end{array}$ & & Categoría ENOE & $\begin{array}{l}\text { Agrupación en } \\
\text { STATA }\end{array}$ & $\begin{array}{c}\text { Fuente para determinar } \\
\text { la variable }\end{array}$ \\
\hline \multirow[b]{2}{*}{ Sexo } & 1 & Hombre & $0=$ Mujer & \multirow{2}{*}{$\begin{array}{c}\text { Rei y Bhattacharya } \\
\text { (2008); Cuevas, De la } \\
\text { Torre y Regala (2016); } \\
\text { OIT (2018) }\end{array}$} \\
\hline & 2 & Mujer & $1=$ Hombre & \\
\hline \multirow{5}{*}{ Edad } & 00 & Menores de un año & \multirow{5}{*}{15 a 96 años } & \multirow{5}{*}{ OIT (2018) } \\
\hline & $00-96$ & Número de años cumplidos & & \\
\hline & 97 & 97 años y más & & \\
\hline & 98 & Edad no especificada & & \\
\hline & 99 & $\begin{array}{l}\text { Edad no especificada para } \\
\text { menores }\end{array}$ & & \\
\hline \multirow{7}{*}{ Estado civil } & 1 & Unión libre & \multirow{7}{*}{$\begin{array}{l}0=\text { Vive con } \\
\text { alguien }(1+5) \\
1=\text { Vive } \\
\text { solo(a) } \\
(2+3+4+6)\end{array}$} & \multirow{7}{*}{$\begin{array}{l}\text { Roldan y Ospino (2009) } \\
\text { Benavides (2018) }\end{array}$} \\
\hline & 2 & Separado(a) & & \\
\hline & 3 & Divorciado(a) & & \\
\hline & 4 & Viudo(a) & & \\
\hline & 5 & Casado(a) & & \\
\hline & 6 & Soltero(a) & & \\
\hline & 9 & No sabe & & \\
\hline Escolaridad & 1 a 24 & $\begin{array}{l}\text { Un año de escolaridad } \\
\text { hasta } 24 \text { años }\end{array}$ & $\begin{array}{l}0 \text { hasta } 24 \text { años } \\
\text { de escolaridad }\end{array}$ & $\begin{array}{c}\text { Lehmann y Zaiceva } \\
\text { (2013); Robles y Martí- } \\
\text { nez (2015); Cuevas, De } \\
\text { la Torre y Regala (2016); } \\
\text { OIT (2018) }\end{array}$ \\
\hline \multirow{4}{*}{$\begin{array}{l}\text { Localidad } \\
\text { (urbano-rural) }\end{array}$} & 1 & Mayores a 100000 habs. & \multirow{4}{*}{$\begin{array}{l}0=\text { Urbano } \\
(1+2+3) \\
1=\text { Rural }(4)\end{array}$} & \multirow{4}{*}{ OIT (2018) } \\
\hline & 2 & De 15000 a 99999 habs. & & \\
\hline & 3 & De 2500 a 14999 habs. & & \\
\hline & 4 & Menores de 2500 habs. & & \\
\hline \multirow{7}{*}{$\begin{array}{l}\text { Tamaño de } \\
\text { empresa }\end{array}$} & 1 & 1 persona & \multirow{3}{*}{$\begin{array}{l}0=\text { Pequeña, } \\
\text { mediana y } \\
\text { grande empresa } \\
(4+5+6)\end{array}$} & \multirow{7}{*}{$\begin{array}{l}\text { Dougherty y Escobar } \\
\text { (2013); Baez (2015) }\end{array}$} \\
\hline & 2 & De 2 a 5 personas & & \\
\hline & 3 & De 6 a 10 personas & & \\
\hline & 4 & De 11 a 15 personas & \multirow{3}{*}{$\begin{array}{l}1=\text { Microem- } \\
\text { presa } \\
(1+2+3)\end{array}$} & \\
\hline & 5 & De 16 a 50 personas & & \\
\hline & 6 & De 51 y más personas & & \\
\hline & 7 & No especificado & & \\
\hline \multirow{4}{*}{ Sector } & 1 & Primario & \multirow{2}{*}{$\begin{array}{l}0=\text { Secundario } \\
\text { y terciario }(2 \\
+3) \\
\end{array}$} & \multirow{4}{*}{ OIT (2018) } \\
\hline & 2 & Secundario & & \\
\hline & 3 & Terciario & \multirow{2}{*}{$\begin{array}{l}1=\text { Primario } \\
\text { (1) }\end{array}$} & \\
\hline & 4 & No especificado & & \\
\hline $\begin{array}{l}\text { Horas de } \\
\text { trabajo }\end{array}$ & $1-168$ & $\begin{array}{l}\text { Número de horas trabaja- } \\
\text { das a la semana }\end{array}$ & $1-168$ & $\begin{array}{c}\text { Cuevas, De la Torre } \\
\text { y Regala (2016); OIT } \\
(2018)\end{array}$ \\
\hline
\end{tabular}

Fuente: elaboración propia con base en INEGI (2020b) y diversos autores. 
Tabla 2: Participación porcentual de los indicadores estratégicos de informalidad laboral en México, 2005.I y 2020.I

\begin{tabular}{|c|c|c|}
\hline Variable & 2005 & 2020 \\
\hline \multicolumn{3}{|l|}{ Grupos de edad } \\
\hline De 15 a 24 años & 24.9 & 19.1 \\
\hline De 25 a 44 años & 43.8 & 41.8 \\
\hline De 45 a 64 años & 25.0 & 31.5 \\
\hline De 65 años o más & 6.3 & 7.6 \\
\hline \multicolumn{3}{|l|}{ Nivel de instrucción } \\
\hline Primaria incompleta & 30.6 & 15.6 \\
\hline Primaria completa & 27.7 & 22.8 \\
\hline Secundaria completa & 28.0 & 36.4 \\
\hline Medio superior y superior & 13.5 & 25.1 \\
\hline \multicolumn{3}{|l|}{ Posición en la ocupación } \\
\hline Trabajadores subordinados y remunerados & 50.4 & 55.2 \\
\hline Empleadores & 2.9 & 3.5 \\
\hline Trabajadores por cuenta propia & 34.7 & 34.1 \\
\hline Trabajadores no remunerados & 11.9 & 7.1 \\
\hline \multicolumn{3}{|l|}{ Sector de actividad económica } \\
\hline Primario & 22.5 & 18.4 \\
\hline Secundario & 23.7 & 21.9 \\
\hline Terciario & 52.6 & 58.8 \\
\hline \multicolumn{3}{|l|}{ Nivel de ingresos } \\
\hline Hasta un salario mínimo & 22.8 & 34.0 \\
\hline Más de 1 hasta 2 salarios mínimos & 27.5 & 34.6 \\
\hline Más de 2 hasta 3 salarios mínimos & 15.0 & 10.0 \\
\hline Más de 3 hasta 5 salarios mínimos & 10.9 & 2.8 \\
\hline Más de 5 salarios mínimos & 3.8 & 0.9 \\
\hline No recibe ingresos & 15.3 & 9.3 \\
\hline \multicolumn{3}{|l|}{ Duración de la jornada de trabajo } \\
\hline Ausentes temporales con vínculo laboral & 3.6 & 2.3 \\
\hline Menos de 15 horas & 9.5 & 10.1 \\
\hline De 15 a 34 horas & 22.3 & 24.0 \\
\hline De 35 a 48 horas & 37.3 & 36.1 \\
\hline Más de 48 horas & 26.6 & 26.5 \\
\hline
\end{tabular}

Nota: los porcentajes no suman 100.0 por ciento debido a que se eliminaron los casos que aparecían como no especificados.

Fuente: elaboración propia con base en INEGI (2020a).

En cuanto a nivel de instrucción refiere, ha disminuido el número de empleos informales con primaria completa respecto del resto de niveles educativos (Tabla 2), no obstante, de 100 por ciento de los trabajadores que no terminaron la primaria más de 85 por ciento es informal (INEGI, 
2020a). Destaca el aumento de ocupados con preparatoria y más estudios, sin embargo, es importante mencionar que, del total de empleos en esta categoría, casi un tercio se ubica en la informalidad para 2005.I y 2020.I (INEGI, 2020a), es decir, que, si se estudian los grupos de forma individual, el menor nivel de instrucción se asocia con el fenómeno de estudio.

Respecto de la posición en la ocupación son los trabajadores subordinados y remunerados quienes concentran el mayor porcentaje de empleos informales (Tabla 2). Aun y cuando los trabajadores por cuenta propia apenas alcanzan un tercio, si se analizan de forma independiente, del total de ellos más de 85 por ciento (para ambos periodos) se ubica en la informalidad (INEGI, 2020a). La situación respecto de los trabajadores no remunerados es más grave: 100 por ciento son informales (INEGI, 2020a) aunque solo constituyan 12 o siete por ciento del total de los empleos informales (Tabla 2).

Cuando de sector de la actividad económica se habla, la Tabla 2 muestra que son los trabajadores del sector terciario quienes por sí solos concentran más de 50 por ciento de los empleos informales, esto se explica porque en realidad más de 58 y 62 por ciento del total de ocupados se hallan en el sector servicios y del comercio (2005.I y 2020.I, respectivamente) (INEGI, 2020a). El grupo que se debe analizar de forma individual es el que corresponde al sector primario porque representan el menor porcentaje, aunque en su interior 90.49 y 86.65 por ciento del total de trabajadores de este sector son informales para los trimestres que se estudian (INEGI, 2020a).

Otra variable de importancia es el nivel de ingreso. En este sentido, los niveles más bajos (sin incluir los que no perciben ingreso) agrupan el mayor porcentaje de empleos informales, es decir, la informalidad se asocia con bajos salarios (Tabla 2). Lo anterior coincide al analizar las clasificaciones: del total de trabajadores que percibe hasta un salario mínimo 92.47 y 84.15 por ciento se ubican en la informalidad (2005.I y 2020.I, respectivamente) (INEGI, 2020a). Quienes no perciben ingreso, presentan porcentajes más bajos respecto del total de la informalidad por nivel de ingreso (Tabla 2); sin embargo, casi 100 por ciento de ellos se ubican en empleos informales en ambos periodos (INEGI, 2020a). Destaca el grupo de trabajadores que perciben entre tres y cinco e incluso más salarios mínimos dado que, de 2005 a 2020 disminuyeron sus porcentajes de participación, lo cual se explica a partir de una disminución del número de ocupaciones totales que percibe estos niveles de ingreso en los últimos 15 años; por ejemplo, los trabajadores que se encuentran en el primer intervalo en cuestión eran más 
de siete millones de ocupados en 2005.I y en 2020.I disminuyeron a 3.7 millones (INEGI, 2020a).

Finalmente, en cuanto a duración de la jornada, más de un tercio de los ocupados en la informalidad, para ambos periodos, se encuentran laborando de 35 a 48 horas (Tabla 1); no obstante, del total de aquellos que se clasifican en Menos de 15 horas, más de 90 por ciento son informales (INEGI, 2020a); aunque su porcentaje es bajo comparado con el resto de las jornadas (Tabla 2).

\section{Resultados del modelo}

Se estimaron ocho modelos para cada trimestre: de forma sucesiva se fueron integrando cada una de las variables independientes a fin de incorporar en el octavo modelo el total de las variables. Con base en las medidas de información que permiten comparar diferentes modelos, el BIC (Bayesian Information Criterion) y el AIC (Akaike Information Criteria) presentaron los resultados menores en el último modelo, que es el que se presenta en la Tabla 3, para ambos periodos, lo que indica que es el de mejor ajuste.

De acuerdo con los resultados (Tabla 3), los modelos son estadísticamente significativos con un $\chi^{2}$ (chi cuadrado) al cinco por ciento. La prueba de bondad de ajuste confirma lo anterior, ya que el pseudo $R^{2}$ fue el mayor en comparación con el resto de los modelos y su valor es de 0.387 y 0.393 para cada periodo correspondiente, lo que confirma que es un buen ajuste. En cuanto a los coeficientes, el estadístico $Z$ señala que las variables son estadísticamente significativas. Para realizar un diagnóstico de cada modelo, se analizaron los logaritmos de la verosimilitud del modelo completo ( $L_{F}$ estimado) versus el modelo que solo incluye a la constante $\left(L_{0}\right.$ estimado): el $L R$ test que es una prueba de $\chi^{2}$ (chi cuadrado), cuya probabilidad se presenta de forma inmediata, indica que la probabilidad de que los coeficientes sean igual con 0 está por debajo de 0.0001 (Escobar, Fernández y Bernardi, 2012), por lo que se rechaza la hipótesis nula y se concluye que al menos uno de los coeficientes de las variables independientes es diferente de 0 , o bien, que las variables independientes tienen efecto sobre la variable dependiente (Tabla 4). 
Características del empleo informal en México, 2005 y 2020 / W. OVANDO ALDANA et al.

Tabla 3: Modelos de regresión logística binaria para el empleo informal en México, 2005.I y 2020.I

\begin{tabular}{|c|c|c|c|c|}
\hline \multirow{2}{*}{ Variable } & \multicolumn{2}{|c|}{2005.1} & \multicolumn{2}{|c|}{ 2020.I } \\
\hline & Coeficientes & Odds ratio & Coeficientes & Odds ratio \\
\hline Sexo $(0=$ mujer $)$ & $0.04594118 * *$ & 1.047013 & $-0.03485994 *$ & 0.9657407 \\
\hline $\begin{array}{l}\text { Edad } \\
\text { (variable continua) }\end{array}$ & $-.02383991 * * *$ & 0.976442 & $-0.0206462 * * *$ & 0.9795655 \\
\hline $\begin{array}{l}\text { Estado civil ( } \\
0=\text { vive con pareja) }\end{array}$ & $.28138529 * * *$ & 1.324964 & $0.25446456^{* * *}$ & 1.289771 \\
\hline $\begin{array}{l}\text { Escolaridad } \\
\text { (variable continua) }\end{array}$ & $-.16188637 * * *$ & 0.8505378 & $-0.17326826^{* * *}$ & 0.840912 \\
\hline Localidad $(0=$ urbana $)$ & $.40652004 * * *$ & 1.501583 & $0.50450317 * * *$ & 1.656162 \\
\hline $\begin{array}{l}\text { Tamaño de empresa ( } 0 \\
\text { = pequeñas, medianas } \\
\text { y grandes empresas) }\end{array}$ & $2.7856175^{* * *}$ & 16.20982 & $2.8968596^{* * *}$ & 18.11716 \\
\hline $\begin{array}{l}\text { Sector }(0=\text { sector } \\
\text { secundario } \\
\text { y terciario })\end{array}$ & $.87898003 * * *$ & 2.408442 & $0.69645326^{* * *}$ & 2.006623 \\
\hline $\begin{array}{l}\text { Horas de trabajo } \\
\text { (variable continua) }\end{array}$ & $-.02669947 * * *$ & 0.9736538 & $-0.0268318^{* * *}$ & 0.973525 \\
\hline _cons & $1.7657453 * * *$ & 5.845927 & $1.9643445^{* * *}$ & 7.130238 \\
\hline $\mathrm{N}$ & 151920 & & 163,776 & \\
\hline $\operatorname{chi} 2$ & 80996.614 & & $89,025.487$ & \\
\hline $\mathrm{r} 2 \_\mathrm{p}$ & 0.38671588 & & 0.39285113 & \\
\hline aic & 128468.73 & & $137,606.31$ & \\
\hline bic & 128558.11 & & $137,696.37$ & \\
\hline
\end{tabular}

legend: $* \mathrm{p}<0.05 ; * * \mathrm{p}<0.01 ; * * * \mathrm{p}<0.001$

Fuente: elaboración propia.

Tabla 4: Medidas de ajuste para el logit de empleo informal

\begin{tabular}{lrr}
\hline & $2005 . \mathrm{I}$ & $2020 . \mathrm{I}$ \\
\hline Log-Lik Full Model: & -64225.366 & -68794.156 \\
LR(8): & 80996.614 & 89025.487 \\
Prob > LR: & 0 & 0 \\
McFadden's Adj R2: & 0.387 & 0.393 \\
Variance of error: & 3.29 & 3.29 \\
Adj Count R2: & 0.606 & 0.625 \\
\hline
\end{tabular}

Fuente: elaboración propia. 
De igual forma, en la Tabla 4, se aprecia el estadístico Adj Count $R^{2}$ : el resultado para ambos periodos permite establecer que este modelo tiene la capacidad de 61 y 63 por ciento de predecir la ubicación de un trabajador en un empleo informal. Lo cual habla de un buen modelo para estos dos trimestres. Además, se incluyen los resultados del pseudo $R^{2}$ o McFadden $R^{2}$ ya comentados con anterioridad.

Una vez que se han analizado las pruebas correspondientes a las estimaciones, se requiere interpretar los resultados, no obstante, es necesario presentar el modelo en forma de razones (odds ratio) como lo indica la Tabla 3. Los resultados obtenidos para estos dos trimestres son muy similares en la mayoría de las variables, en otras palabras, el empleo informal en México presenta las mismas características con semejantes probabilidades de ocurrencia en 15 años. Mención aparte merece la variable sexo cuyo coeficiente y valor de odd ratio cambia de un periodo a otro: es positivo y mayor a 1 en 2005.I y, negativo y menor a 1 en 2020.I. Es decir, para el primer trimestre en cuestión su relación es positiva respecto de la informalidad: cuando el trabajador es hombre la razón de ubicarse en un empleo informal es 1.047:1 de cuando se es mujer, es decir, tiene mayor probabilidad el hombre de ubicarse en un empleo informal (Tabla 3). Recuérdese que se consideró a los hombres como la variable que presenta el atributo porque es mayor el número total de trabajadores en el empleo informal, sin embargo, dentro de los grupos por sexo, son las mujeres quienes tienen mayor porcentaje respecto de su total en este tipo de empleos. En lo que respecta al trimestre en comparación (2020.I): cuando el trabajador es hombre, la razón de ubicarse en un empleo informal es 0.966:1, lo que sugiere menores probabilidades en comparación con las mujeres (Tabla $3)$. En esta variable se encuentran dos aspectos interesantes: por un lado, los resultados de 2005 coinciden con lo establecido con la OIT (2018): para los países emergentes y en desarrollo, así como para los países desarrollados, la principal fuente de empleo para los hombres se ubica en el informal. Por otro lado, los resultados de 2020 son congruentes con lo mencionado por Rei y Bhattacharya (2008) y por Elgin y Elveren (2019), quienes señalan que las mujeres tienen mayor probabilidad de ubicarse en un empleo informal; situación asociada con la decisión, en algunos casos, de mantener en equilibrio las actividades del hogar y el empleo informal.

El resto de las variables que presentaron valores de odds ratio mayores a uno fueron: estado civil, localidad, tamaño de la empresa y sector. En el primer caso, si se vive solo (separado, divorciado, viudo o soltero) aumenta la razón de encontrarse en un empleo informal 1.325:1 y 1.290:1 (2005.I 
y 2020.I) respecto a si se vive acompañado (casado y en unión libre) (Tabla $3)$. Una forma de corroborar lo precedente es con el cálculo del promedio de los efectos marginales (PEM) ${ }^{1}$ : la probabilidad de localizarse en un empleo informal es 3.7 y 3.4 puntos porcentuales mayores para quienes viven solos que para quienes no (con características medias en el resto de las variables) (ver Tabla 5). Roldan y Ospino (2009) y, Rivera y Benavides (2018) coinciden con lo hallado: las personas casadas se vinculan menos con la informalidad. Probablemente, los casados tienen una mayor preocupación por el futuro conyugal y familiar relacionado con la seguridad laboral debido a la responsabilidad que implica ser madres o padres de familia.

Tabla 5: Promedio de los efectos marginales de las variables categóricas

\begin{tabular}{lcr}
\hline Variable & \multicolumn{2}{c}{$\mathrm{dy} / \mathrm{dx}$} \\
\hline Sexo $(0=$ mujer $)$ & 0.006117 & -0.004595 \\
Estado civil $(0=$ vive con pareja $)$ & 0.037465 & 0.033542 \\
Localidad $(0=$ urbana $)$ & 0.054125 & 0.066501 \\
Tamaño de la empresa & 0.370886 & 0.381848 \\
$(0=$ pequeñas, medianas y grandes empresas $)$ & & \\
Sector $(0=$ sector secundario y terciario $)$ & 0.117030 & 0.091803 \\
\hline
\end{tabular}

Fuente: elaboración propia.

Por lo que concierne a la variable localidad, si el empleado se localiza en una zona rural incrementa la razón para hallarse en la informalidad 1.502 y 1.656 a uno en relación con quienes viven en zonas urbanas (2005 y 2020) (Tabla 3). Lo anterior se confirma con el cálculo del PEM: la probabilidad de encontrase en un empleo informal es 5.4 y 6.7 puntos porcentuales mayores para quienes viven en una localidad rural que para quienes lo hacen en una zona urbana (Tabla 5). Estos resultados coinciden con lo que plantea la OIT (2018) el ubicarse en una zona rural incide más en hallarse en la informalidad que si se encuentra en una zona urbana. Para este caso, es importante mencionar que en América Latina existen diferencias entre las zonas urbanas y las rurales referidas, principalmente en cuanto al nivel de ingreso; debido a que en las segundas predominan los trabajos por cuenta propia y trabajo auxiliar no remunerado. Asimismo, la

${ }^{1}$ El efecto marginal de una variable independiente es la derivada de una función dada — de las covariables y coeficientes- (STATA, 2021). Sin embargo, en las variables continuas, el cálculo del efecto marginal es menos útil y más difícil de interpretar (Williams, 2021), por lo que en este documento solo se presentan tales afectos para las variables categóricas. 
seguridad social y la existencia de contrato son aspectos poco favorables para las zonas rurales (Reinecke y Faiguenbaum, 2016). En otras palabras, los puestos de trabajo asociados con las zonas rurales tienen mayor probabilidad de ubicarse en la informalidad.

En cuanto al tamaño de la empresa, si el trabajador se ubica en una de tamaño micro, la razón de hallarse en un empleo informal es 16.210 y 18.117 a uno en comparación con quienes laboran en una pequeña, mediana y gran empresa (Tabla 3). De hecho, el PEM es el mayor para esta variable: la probabilidad de encontrarse en un empleo informal es 37.1 y 38.2 puntos porcentuales mayores para quienes trabajan en una microempresa respecto de quienes laboran en los otros tamaños de empresas (ver Tabla 5). Las microempresas se vinculan con el empleo informal como lo señalan Dougherty y Escobar (2013) y Baez (2015).

Referente al sector de la actividad económica, si el empleado labora en el sector primario la razón de ubicarse en la informalidad es 2.408 y 2.007 veces mayor que si se trabaja en las actividades secundarias y terciarias (Tabla 3). Más aún, la probabilidad de ubicarse en un empleo informal es 11.7 y 9.2 puntos porcentuales mayores para quienes trabajan en actividades del primer sector respecto de quienes trabajan en la industria manufacturera, el comercio y los servicios (Tabla 5). Importante de recordar que, en el apartado anterior, se observó que por sector de la actividad económica el mayor porcentaje de empleo informal se encuentra en el terciario (servicios y comercio) con más de 50 por ciento de los trabajadores (Tabla 2). No obstante, los resultados confirman que es el primario, el que de forma individual de 100 por ciento de sus trabajadores más de 80 por ciento son informales. En México, para el primer trimestre de ambos años de estudio, 100 por ciento de los trabajadores por cuenta propia y no remunerados del ámbito agropecuario son informales (INEGI, 2020b), por lo que la categoría ocupacional explica por qué este sector se relaciona con la informalidad.

Finalmente, las variables que presentaron valores de odds ratio menores a uno (relación negativa respecto del empleo informal) fueron: edad, escolaridad y horas de trabajo, todas ellas variables continuas, cuya interpretación es diferente. Para analizar facilitar la obtención de la probabilidad de ocurrencia del evento (ubicarse en un empleo informal), los odds ratio se dividieron entre (1+odds ratio $)^{2}$. Por ejemplo: en la variable edad, el resultado para ambos periodos es de 0.494 y 0.495 lo que indica que al aumentar un año la edad del trabajador disminuye la probabilidad de

2 Ver Silva y Barroso (2004). 
ubicarse en un empleo informal en 0.5. Es decir, conforme aumenta la edad disminuye la probabilidad de laborar en un empleo informal lo que concuerda con la OIT (2018): los empleos informales se asocian con los jóvenes más que con el resto de los grupos etarios. De hecho, son los jóvenes los más vulnerables para hallar trabajos precarios (Román, 2013; OIT, 2015b); ya sean formales o informales, y, por lo general cuando consiguen un trabajo lo encuentran en la informalidad (OIT, 2015b). Algunas de las razones por la cuales son los jóvenes más propensos a situarse en un empleo informal se vinculan con menos años de educación y mayor residencia rural en comparación con quienes tienen empleos formales.

En relación con los años de escolaridad, la probabilidad de que un trabajador se halle en un empleo informal cuando aumenta un año de escolaridad disminuye 0.460 y 0.457 . Lo anterior suma a lo ya encontrado por otras investigaciones (García, 2011, Lehmann y Zaiceva, 2013; Robles y Martínez, 2018; Cuevas, De la Torre y Regla, 2016; OIT, 2018): mayor nivel de escolaridad reduce la probabilidad de estar en la informalidad, en otras palabras, el trabajo no calificado presenta mayor dificultad para encontrar un empleo formal, precisamente por la falta de cualificación.

Finalmente, la probabilidad de un individuo de encontrarse en un empleo informal cuando aumenta una hora de trabajo disminuye en 0.493 para ambos periodos. Este resultado confirma lo expuesto por De la Torre y Regla (2016): "el trabajador informal trabaja menos horas en comparación con el formal porque, al carecer de un contrato, la jornada de trabajo es más flexible para los informales".

Para determinar cuál variable incrementa en mayor medida la probabilidad de ubicarse en un empleo informal, Escobar, Fernández y Bernardi (2012) recomiendan que a los valores de las razones menores a uno obtenerles su inverso, es decir, dividir uno entre los odds ratio. En la Tabla 6 se muestra en negritas los resultados a los cuales se les calcularon los inversos.

De acuerdo con los resultados y los datos que se obtuvieron para estos dos trimestres, el efecto del tamaño de la empresa en el empleo informal es mayor que el resto de las variables. Lo descrito se asocia con lo expuesto por la versión estructuralista sobre el estudio de la informalidad: lo formal y lo informal se encuentra unido y es el sistema capitalista el que fomenta esta informalidad a través de la subcontratación de empresas informales (Portes y Benton, 1987). En importancia también se encuentra el sector de la actividad económica, es decir, hallarse laborando en el sector primario es la segunda razón en importancia por la cual un(a) trabajador(a) se ubi- 
caría en un empleo informal. La localidad, en este caso, rural, es la tercera característica que influye en la ubicación de un trabajador(a) en un empleo informal. Finalmente, le siguen estado civil (soltero), grado de escolaridad, sexo, horas de trabajo y edad como último rasgo, que inciden en hallarse en un empleo informal. En otras palabras, las peculiaridades del trabajador no influyen tanto en su ubicación en un empleo informal, más bien son las propias características del mercado.

Tabla 6: Comparación de los odds ratio para el empleo informal

\begin{tabular}{lrr}
\hline Variable & 2005.I & $2020 . \mathrm{I}$ \\
\hline Sexo $(0=$ mujer $)$ & 1.047013 & 1.0354746 \\
Edad (variable continua) & 1.0241264 & 1.0208608 \\
Estado civil ( $0=$ vive con pareja) & 1.324964 & 1.289771 \\
Escolaridad (variable continua) & 1.1757267 & 1.1891851 \\
Localidad ( 0 = urbana) & 1.501583 & 1.656162 \\
Tamaño de la empresa (0 = pequeñas, & 16.20982 & 18.11716 \\
medianas y grandes empresas) & 2.408442 & 2.006623 \\
Sector $(0=$ sector secundario y terciario) & 1.0270591 & 1.027195 \\
\hline Horas de trabajo (variable continua) & & \\
\hline
\end{tabular}

Fuente: elaboración propia.

\section{Conclusiones}

El empleo informal es un fenómeno de gran relevancia económica y social en las economías del mundo. Por un lado, permite absorber la mano de obra que no se incorpora a las actividades formales, es decir, amortigua el desempleo y, al mismo tiempo, permite que los trabajadores accedan a una fuente de ingreso. Por otro, se conforma, principalmente, de actividades de baja productividad, afectando el crecimiento de largo plazo y, en el caso de quienes viven la informalidad, las condiciones de trabajo poco favorables como: ausencia de un contrato de trabajo, poca seguridad dentro de las actividades laborales, nulos o escasos servicios de seguridad social y protección laboral, menor nivel de ingresos respecto de los empleos formales, entre otras características. No obstante, identificar los rasgos del empleo informal es una tarea complicada dada su diversidad que comprende desde atributos económicos y laborales hasta sociodemográficos incluyendo de ubicación de residencia. En otras palabras, la informalidad se asocia con 
múltiples factores y diversos tipos de empleo informal: cuenta propia, trabajadores(as) del hogar, trabajo de autoconsumo agropecuario, entre otras, que complejizan su estudio.

Investigaciones realizadas en el mercado de trabajo en México, hasta este momento, han evidenciado diversos determinantes del empleo informal de forma separada como son: sexo, edad, estado civil, escolaridad, localidad, tamaño de empresa, sector de la actividad económica, horas de trabajo, corrupción, nivel de ingreso, regiones marginadas, incentivos para la inversión, entre otras características. El presente documento articuló la mayoría de ellos, a saber: sexo, edad, estado civil, escolaridad, localidad, tamaño de empresa, sector de la actividad económica y horas de trabajo en dos momentos del tiempo, en 2005 y 2020 en su primer trimestre. A partir de un modelo de regresión logística binaria y con datos de la ENOE, se encontraron casi nulos cambios en el peso relativo de cada una de las variables en 15 años. Además, se identificaron aquellas que incrementan la probabilidad de ubicarse en un empleo informal.

Uno de los principales hallazgos, es que el efecto del tamaño de la empresa en el empleo informal fue el mayor en comparación con el resto de las variables. En otras palabras, las microempresas tienen mayor incidencia en los empleos informales. Estos resultados apoyan los argumentos que versan sobre la predominancia de las microempresas en la informalidad y, debido al resultado de los odds ratio en comparación con el resto de las variables, se confirma como una variable proxy de la informalidad. Algunos factores relacionados con este tamaño de empresa que impulsan la informalidad son los costos de comenzar un negocio (Dougherty y Escobar, 2013) y la corrupción (Dougherty y Escobar, 2013; Baez, 2015). Como lo establece la visión voluntarista o parásito, el análisis de costo beneficio que realizan los empresarios les impulsa a estar en la informalidad. Empero, ambos rasgos son responsabilidad del Gobierno en sus diferentes niveles, es decir, atenuar la informalidad desde el tamaño de la empresa es tarea de los hacedores de política pública. El Doing Business 2020 (World Bank Group, 2019) reporta a la economía mexicana como el líder regional en América Latina en cuanto a la facilidad para hacer negocios; en cambio, aún se encuentra por debajo de las diez economías mejor posicionadas con casi 12 puntos porcentuales. Entre los aspectos que pueden mejorarse están: tarifas para permiso de construcción, o bien, modificaciones a los contratos (como el de construcción); las primeras aumentaron y las segundas abarcan más de 100 días en resolverse contra economía como Finlandia o Corea que solo requieren tres semanas. Lo recomendable es revisar los 
trámites y el costo para poder iniciar un negocio, en otras palabras, se trata de simplificar el registro de las empresas y acceder a financiamiento. Sin embargo, lo anterior no tendría sentido si la corrupción está inmersa entre los funcionarios públicos. Resolver ambas problemáticas no es una tarea de corto plazo, pero sí de voluntad por parte del Gobierno federal, estatal y municipal. Como menciona Rose-Akerman (2019) la idea es disminuir los beneficios que genera la corrupción y elevar el precio de la acción ilegítima, o bien, aumentar los relacionados con la legítima.

Además, se ha hallado que laborar en el sector primario de la actividad económica, así como en una zona rural inciden en tener un empleo informal. Estos dos aspectos de la informalidad están estrechamente relacionados porque es en las zonas rurales donde se llevan a cabo actividades relacionadas con el campo: agricultura, ganadería, silvicultura, etcétera. De acuerdo con la Comisión Nacional de los Salarios Mínimos (CONSAMI, 2020), más de dos millones de personas en México son jornaleros agrícolas quienes en su mayoría no cuentan con contrato de trabajo ni acceden a servicios de salud por parte de quien los contrata. Es decir, la zona rural y sus actividades económicas colocan al trabajador en una situación de informalidad.

Otros de los resultados permiten establecer que el estar soltero, carecer de preparación educativa, ser joven y laborar pocas horas se relacionan con la informalidad, pero en menor medida que el tamaño de la empresa, la zona rural y el sector de la actividad económica. Las dos primeras variables, estado civil y nivel educativo, fueron de las características sociodemográficas con mayor incidencia en la probabilidad de hallarse en un empleo informal. La primera es un rasgo que depende del individuo quien decide cómo vivir: con pareja o sin ella. Derivado de lo anterior es que el estar casado o vivir en unión libre implica mayor responsabilidad con la pareja y más aún si se tienen hijos; por lo que un empleo formal respaldaría ese cometido. La segunda está asociada con las características económicas y sociales de la familia: hay niños, adolescentes y jóvenes que abandonan los estudios por sumar un ingreso más a la familia. Estudiar se convierte, para ellos, en una segunda opción, y, la forma de acceder al mercado de trabajo con la carencia de estudios o bajo nivel educativo es, por lo general, mediante un empleo informal. Mientras que aquellos que logran un nivel educativo superior pueden ubicarse con mayor probabilidad en un empleo formal.

Trato especial merecen las variables sexo, horas de trabajo y edad, cuyos valores en los odds ratio fueron los más bajos. En lo concerniente al 
sexo, su coeficiente cambió de signo de un periodo a otro. Mientras que en 2005.I se observó una mayor probabilidad de ubicarse en el empleo informal para los hombres respecto a las mujeres, en 2020.I se invirtió, lo cual sugiere que es indistinto el sexo del trabajador para ubicarse en el empleo informal.

En consideración a horas de trabajo, variable relacionada con la demanda, se presentó un signo positivo en la asociatividad con el empleo informal. Las jornadas de trabajo de pocas horas se corresponden más con la informalidad porque es considerado un trabajo flexible (Cuevas, De la Torre y Regla, 2016; Portes, 1995), lo que significa que quien contrata puede disponer del trabajador respecto de las horas en el trabajo variando su jornada en función de las circunstancias del mercado; en cambio, quienes laboran más horas tienen mayor probabilidad de ubicarse en un empleo formal; puesto que hay jornadas de trabajo (legales) impuestas por el patrón que pueden promediar 45 horas a la semana en contraste con las 38 horas de los empleos informales (Cuevas, De la Torre y Regla, 2016)

Finalmente, la variable edad también presentó un nexo positivo con el empleo informal. Ciertamente son los jóvenes quienes se relacionan más con la informalidad debido a que se les considera como "mano de obra secundaria" (Román, 2013: 167). La experiencia que se adquiere a lo largo de la vida productiva, conforme se incrementa la edad, permite incrementar el conocimiento y destreza de cada individuo y, de esta forma, acceder a empleos con mejores condiciones laborales como lo podría ser uno de tipo formal.

Los hallazgos de la presente investigación indican que las características del trabajador tienen menor incidencia en la informalidad en comparación con las peculiaridades de la demanda de trabajo, en este caso, las microempresas. Son ellas quienes condicionan el ser informal o no, por lo tanto, las políticas públicas deben estar encaminadas a incentivar la formalización de éstas, pero con la idea de que no se queden en este tamaño, sino motivar su crecimiento mediante algunas de las formas que ya se mencionaron.

Con base en lo planteado en líneas anteriores, se recomienda ampliamente, para investigaciones futuras, analizar a las microempresas, así como a la zona rural y la actividad primaria para determinar los factores que les asocia con la informalidad, ya que los costos sociales y económicos son altos, máxime que en 15 años la estructura de los determinantes de la informalidad presentó escasa variación. De igual forma, se sugiere dividir el estudio por sexo y tratar a las variables continuas de edad y horas de 
trabajo de forma diferente como puede ser la categorización que permita identificar rasgos particulares por grupos etarios o bien por jornadas de trabajo.

Asimismo, se sugiere estudiar causas y efectos de la informalidad y, sobre todo, analizar el mercado de trabajo antes y después de la pandemia Covid-19 debido al cierre de empresas y despido de trabajadores por el cese de actividades económicas.

\section{REFERENCIAS BIBLIOGRÁFICAS}

Agresti, Alan, 2007, An Introduction to Categorical Data Analysis, John Wiley andSons, Inc, United States of America.

Baez, Antonio, 2015, Determinants of Micro Firm Informality in Mexican States 2008-2012, AQR 15/09, Working Papers, The Research Institute of Applied Economics (IREA), Barcelona. Disponible en http://diposit.ub.edu/dspace/bitstream/2445/66925/1/IR15-014_BaezMorales.pdf

Buis, Maarten L., 2017, "Logistic regression: When can we do what we think we can do?", Unpublished note, University of Konstanz: 1-19.

CEPAL, 2019, Coyuntura Laboral en América Latina y el Caribe. El futuro del trabajo en América Latina y el Caribe: antiguas y nuevas formas de empleo y los desafios para la regulación laboral, Comisión Económica para América Latina y el Caribe, Santiago.

Chen, Martha, 2012, "La economía informal: definiciones, teorías y políticas", Documento de trabajo. Mujeres en empleo informal: globalizado y organizado, WIEGO.

Chen, Marty, 2005, "Rethinking the informal economy: From enterprise characteristics to employment relations", in Kudva, Neema, and Beneira, Lourdes (editors), Rethinking Informalization. New York: Cornell University.

CONASAMI, 2020, "La pandemia del Covid-19 exhibe la indefensión y precariedad de millones de jornaleros agrícolas", en Boletín No. 10/2020, Comisión Nacional de los Salarios Mínimos, México.

Cuevas, Enrique, De la Torre, Hugo Antolín y Regla, Saúl Oswaldo, 2016, Características y determinantes de la informalidad laboral en México, Universidad Autónoma de Ciudad Juárez, México.

De la Garza, Enrique, 2011 "Problemas conceptuales, relaciones de trabajo y derechos laborales de los trabajadores informales", en Realidad, datos y espacio, Revista Internacional de Estadística y Geografia, 2(3): 5-15.

De Soto, Hernando, 1995, “¿Por qué importa la economía informal?”, El sector informal en América Latina: Dos décadas de análisis. Consejo Nacional para la Cultura y las Artes, México.

Dore-Carbal, Carlos, 1995, "Introducción”, en Portes, Alejandro (1995), En torno a la informalidad: Ensayos sobre teoría y medición de la economía no regulada, FLACSO México - Miguel Ángel Porrúa, México. 
Dougherty, Sean, and Escobar, Octavio, 2013, The determinants of informality in Mexico's states, OECD, disponible en https://doi.org/10.1787/5k483jrvnjq2-en

Elgin, Ceyhun, and Elveren, Adem Yavuz, 2019, Informality, Inequality, and Feminization of Labor, University of Massachusetts, Amherst, Political Economy Research Institute, USA.

Escobar, Modesto; Fernández, Enrique y Bernardi, Fabrizio, 2012, Análisis de datos con STATA, Centro de Investigaciones Sociológicas, España.

García, Gustavo Adolfo, 2011, "Determinantes macro y efectos locales de la informalidad laboral en Colombia”, en Sociedad y Economía, (21): 69-98.

Hart, Keith, 1973, "Informal Income Opportunities and Urban Employment in Ghana", in The Journal of Modern African Studies, 11(1): 61-89.

Hussmanns, Ralp, 2004, Statistical definition of informal employment: Guidelines endorsed by the Seventeenth International Conference of Labour Statisticians (2003), International Labour Organization, Switzerland.

ILO, 1993, Fifteenth International Conference of Labour Statisticians. Statistics of employment in the informal sector, International Labour Organization, Geneva.

ILO, 2002, International Labour Conference 90th Session. Decent work and the informal economy, International Labour Organization, Geneva.

INEGI, 2014, La informalidad laboral: Encuesta Nacional de Ocupación y Empleo: marco conceptual y metodológico, Instituto Nacional de Estadística y Geografía, México.

INEGI, 2020a, Indicadores de informalidad laboral, Instituto Nacional de Estadística y Geografía, México. Disponible en https:/www.inegi.org.mx/programas/ enoe/15ymas/, Consultado el 10/08/2020,

INEGI, 2020b, Encuesta Nacional de Ocupación y Empleo (ENOE) población de 15 años y más de edad, Instituto Nacional de Estadística y Geografía, México. Disponible en https://www.inegi.org.mx/programas/enoe/15ymas/, Consultado el 10/08/2020,

Infante, Ricardo y Klein, Emilio, 1991, "Mercado Latinoamericano del trabajo en 1950-1990”, en Revista de la CEPAL, (45): 129-144.

Kuha, Jouni, and Mills, Colin, 2020, "On group comparisons with logistic regression models", Sociological Methods \& Research, 49(2): 498-525.

Lehmann, Hartmut, and Zaiceva, Anzelika, 2013, Re-defining informal employment and measuring its determinants: evidence from Russia.

Levy, Santiago, 2018, Esfuerzos mal recompensados: la elusiva búsqueda de la prosperidad en México. Banco Interamericano de Desarrollo, Washington.

Lewis, William Arthur, 1954, "Economic Development with Unlimited Supplies of Labour", in The Manchester School of Economic and Social Studies, 22(2): 139-191. https://doi.org/10.1111/j.1467-9957.1954.tb00021.x 
Loría, Eduardo, Aupart, Malinalli y Salas, Emmanuel, 2016, "Informalidad, productividad y crecimiento en México, 2000”, en Ensayos. Revista de economía 35(2): 151-174.

Neffa, Julio César, 2008, Sector informal, precariedad, trabajo no registrado, $9^{\circ}$ Congreso Nacional de Estudios del Trabajo, Argentina.

OECD, 2017, How does Mexico compare? Employment Outlook 2017, Organisation for Economic Co-operation and Development. Online https://www.oecd.org/ mexico/Employment-Outlook-Mexico-EN.pdf

OIT, 2013, La Economía Informal y el Trabajo Decente: Una guía de recursos sobre políticas. Apoyando la transición hacia la formalidad, Organización Internacional del Trabajo, Turín.

OIT, 2014, El empleo informal en México: situación actual, políticas y desafios, Organización Internacional del Trabajo, Oficina Regional para América Latina y el Caribe.

OIT, 2015a, Indicadores clave del mercado de trabajo. Novena edición. Disponible en https://www.ilo.org/global/statistics-and-databases/research-and-databases/ kilm/WCMS_498940/lang--es/index.htm

OIT, 2015b, Juventud e informalidad: formalizando la informalidad juvenil Experiencias innovadoras en América Latina y el Caribe, Organización Internacional del Trabajo, Oficina Regional para América Latina y el Caribe, Perú.

OIT, 2016, Panorama Laboral 2016 América Latina y el Caribe, Organización Internacional del Trabajo, Perú.

OIT, 2017, Empleo y trabajo decente en situaciones de fragilidad, conflicto y desastre: Guía, Organización Internacional del Trabajo, Ginebra.

OIT, 2018, Mujeres y hombres en la economía informal: un panorama estadístico (tercera edición), Organización Internacional del Trabajo, Ginebra.

Perry, Guillermo, Maloney, William F., Arias, Omar S., Fajnzylber, Pablo, Mason, Andrew D. y Saavedra-Chanduvi, Jaime, 2007, Informalidad: escape y exclusión. Estudios del Banco Mundial sobre América Latina y el Caribe. Banco Mundial, Washington, D. C.

Porta, Rafael La, and Shleifer ,Andrei, 2008, The unofficial economy and economic development. National Bureau of Economic Research, US.

Portes, Alejandro, 1995, En torno a la informalidad: Ensayos sobre teoría y medición de la economía no regulada, FLACSO México - Miguel Ángel Porrúa, México.

Portes, Alejandro, y Lauren Benton, 1987, "Desarrollo industrial y absorción laboral: una reinterpretación”, en Estudios sociológicos, 5(13): 111-137.

Rei, Diego, and Bhattacharya, Manas, 2008, The impact of institutions and policy on informal economy in developing countries: an econometric exploration, ILO Working Papers, International Labour Organization, Geneva. 
Reinecke, Gerhard, y Faiguenbaum, Sergio, 2016, “Empleo rural en América Latina: avances y desafíos", en Nueva Sociedad, Fundación Friedrich Ebert.

Rivera, Andrés Julián y Benavides, Luis Eduardo, 2018, Relaciones y variables que inciden en la informalidad laboral en la ciudad de Bogotá (2017): una aproximación estructural y econométrica, Universidad de la Salle, Bogotá.

Robles, David y Martínez, Miguel Ángel, 2018, "Determinantes principales de la informalidad: un análisis regional para México", en Región y Sociedad, 30(71): $1-35$.

Roldán, Paola y Ospino, Carlos, 2009, “¿Quiénes terminan en la informalidad?: impacto de las características y el tiempo de búsqueda", en Revista de Economía del Caribe, (4): 149-180.

Román, Yuliana Gabriela, 2013, “Impactos sociodemográficos y económicos en la precariedad laboral de los jóvenes en México", en Región y sociedad 25(58): 165-202.

Rose-Ackerman, Susan, 2019, "Corrupción y competencia", en Revista de Ciencia Política 18(1-2): 43-51.

Salas, Manuel, 1996, "La regresión logística. Una aplicación a la demanda de estudios universitarios”, en Estadística Española, 38(141): 193-217.

Samaniego, Norma, 2008, "El crecimiento explosivo de la economía informal” en Economía unam, 5(13): 30-41.

Silva, Luis Carlos y Barroso, Isabel María, 2004, Regresión Logística, Cuadernos de Estadística 15, Arco Libros-La Muralla, Madrid.

STATA, 2021, Obtaining marginal effects after estimations with interactions. Disponible en https:/www.stata.com/support/faqs/statistics/marginal-effects-after-interactions/

Tokman, Víctor, 1982, "Desarrollo desigual y absorción de empleo. América Latina 1950-1980", en Revista de la CEPAL, (17): 129-142.

Tokman, Víctor, 2004, Una voz en el camino. Empleo y equidad en América: 40 años de búsqueda. Fondo de Cultura Económica, México.

Tokman, Víctor, 2008, Flexiguridad con informalidad: opciones y restricciones, CEPAL.

Train, Kenneth, 2002, Discrete Choice Methods with Simulation, Cambridge University Press, United Kingdom, 378 pp.

Vanek, Joann, Chen, Martha, Carre, Francoise, Carré, Heintz, James, and Hussmanns, Ralp, 2014, Statistics on the Informal Economy: Definitions, Regional Estimates and Challenges, Working Paper (Statistics), WIEGO.

Varela, Rogelio, Castillo, Ramón A. y Ocegueda, Juan Manuel, 2013, "El empleo formal e informal en México: un análisis discriminante", en Papeles de población, 19(78): 111-140. 
Weller, Jürgen, 1998, "La evolución del empleo en América Latina en los años noventa”, en Papeles de Población, 4(18): 9-47.

Williams, Richard, 2021, Marginal Effects for Continuous Variables, University of Notre Dame. Disponible en https://www3.nd.edu/ rwilliam/stats3/Margins02. pdf

World Bank Group, 2019, Doing Business 2020, The World Bank, Washington.

\section{RESUMEN CURRICULAR DE LAS AUTORAS}

\section{Wendy Ovando Aldana}

Doctora en Ciencias Económico-Administrativas por la Universidad Autónoma del Estado de México (UAEMéx). Maestra en Estudios Urbanos y Regionales por la UAEMéx y Licenciada en Economía, también por la UAEMéx. Profesora de tiempo completo en la Facultad de Economía de la UAEMéx. Miembro del Sistema Nacional de Investigadores (SNI) Nivel 1. Línea de investigación: Desarrollo Económico y Social. Temas: flexibilidad laboral y empleo informal.

Dirección electrónica: wovandoa@uaemex.mx

Registro ORCID: https://orcid.org/0000-0003-0793-6971

\section{Celso Rodrigo Rivera Rojo}

Egresado del Doctorado en Ciencias Económico-Administrativas por la Universidad Autónoma del Estado de México (UAEMéx); Maestro en Finanzas Corporativas por la UAEMéx y Licenciado en Administración por la misma institución. Líneas de investigación: Economía institucional y costos de transacción.

Dirección electrónica: criverar@uaemex.mx

Registro ORCID: https://orcid.org/0000-0001-6302-5051

\section{María del Carmen Salgado Vega}

Doctora en Estructura Económica, Desigualdad Social y Políticas Públicas por la Universidad de Salamanca, España. Maestra en Desarrollo Regional por la Universidad Autónoma del Estado de México (UAEMéx) y Licenciada en Economía por la UAEMéx. Profesora Investigadora de la Facultad de Economía de la Universidad Autónoma del Estado de México. Líneas de Investigación: Desarrollo Económico y Social. Temas: Desarro1lo Regional, Mercado de Trabajo y Educación.

Dirección electrónica: casa1961@uahoo.com.mx

Registro ORCID: https://orcid.org/0000-0002-8290-2221

Artículo recibido el 4 de diciembre de 2020 y aprobado el 24 de junio de 2021. 